\title{
Crenças de pessoas hipertensas sobre barreiras e benefícios para o controle da doença
}

\author{
Cláudia Geovana da Silva Pires, M.Sc.*, Renata Pacheco Reis**, Fernanda Carneiro Mussi, D.Sc.***
}

*Enfermeira do Hospital Sáo Rafael e Docente da Universidade do Estado da Babia, **Aluna do Curso de Graduação em Enfermagem da UFBA, Bolsista PIBIC-UFBA, financiada pela Fundação de Amparo a Pesquisa do Estado da Bahia 20062007, ***Enfermeira, Professora da Escola de Enfermagem da UFBA

\begin{abstract}
Resumo
A pesquisa descritiva-exploratória identificou crenças em saúde sobre barreiras e benefícios relacionados às medidas de controle da hipertensão arterial, adotando como referencial teórico o Modelo de Crenças em Saúde. Foram entrevistados 106 adultos negros e hipertensos em um centro de saúde, em Salvador, utilizando-se uma Escala Likert de Crenças em Saúde. Os dados foram analisados em números absolutos e percentuais. Evidenciou-se que para comer menos doce, verificar a pressão arterial, manter peso ideal e parar de fumar predominaram benefícios em todas as sentenças e barreiras em 3 das 5 referentes a cada medida. Em todas as sentenças relativas a evitar preocupação e ter tempo para relaxamento predominaram benefícios e barreiras. Nas sentenças sobre benefícios para evitar bebidas alcoólicas, praticar exercício e consultar o médico houve maior percepçáo de benefícios. Todavia, respectivamente a essas medidas, identificou-se em 1 das 5,6 das 9 e 1 das 5 sentenças sobre barreiras maior percepçâo de barreira. Nas 6 das 7 sentenças sobre benefícios para usar pouco sal, usar pouca gordura e ter horas de lazer/diversão houve maior percepção de benefícios, porém, respectivamente a essas medidas houve maior percepção de barreira em 3 das 4, 5 das 6 e 1 das 2 sentenças sobre barreiras. Para a maioria das medidas estudadas predominou crenças sobre benefícios e identificou-se indicadores para adesão ao tratamento.
\end{abstract}

Palavras-chave: hipertensão, educação em saúde, enfermagem.

\section{Abstract \\ Health belief of hypertensive people about barriers and benefits for controlling the disease}

This study identified popular beliefs in health about barriers and benefits related to arterial hypertension control, adopting as a theoretical reference the Health Belief Model. 106 adult hypertensive negro people were interviewed at a health center in Salvador, using the Likert Health Belief Scale. The information was analyzed in absolute values and percentages. It was evidenced that eating less sugar, verifying blood pressure, maintaining the ideal weight and quitting smoking predominated as benefits in all sentences and as barriers in 3 out of 5 relating to each measure. In all sentences relating to avoiding worries and having time for relaxing, predominated benefits and barriers. In the sentences about benefits of avoiding alcoholic beverages, practicing exercises and consulting a doctor, were identified in 1 of 5, 6 of 9 and 1 of 5 sentences about barriers, 
greater perception of barriers. Of the 6 and 7 sentences about the benefits of using less salt, less fat and having leisure/fun hours, there was a greater perception of benefits, nevertheless, respectively, to these measures, there was a greater perception of barriers in 3 of 4,5 of 6 and 1 of 2 sentences about barriers. For most of the measures studied, the health beliefs on benefits predominated and indicators for adherence to the treatment were identified.

Key-words: hypertension, health education, nursing.

\section{Resumen \\ Creencia de personas hipertensas sobre las barreras y beneficios para el control de la enfermedad}

La investigación descriptiva-exploratoria identificó creencias en la salud sobre barreras y beneficios relacionados a las medidas de control de la hipertensión arterial, adoptando como referencial teórico el Modelo de Creencias en la Salud. Fueron entrevistados 106 adultos negros e hipertensos de un centro de salud, en Salvador, utilizándose la Escala Likert de Creencias en la Salud. Los datos analizados fueron en números absolutos y porcentuales. Evidenciase que comer menos dulce, verificar la presión arterial, mantener el peso ideal y parar de fumar predominaran beneficios en todas las sentencias y barreras en 3 de las 5 referentes a cada medida. En todas las sentencias relativas a evitar preocupaciones y tener tiempo para relajamiento predominaran beneficios y barreras. En las sentencias sobre beneficios de evitar bebidas alcohólicas, practicar ejercicio y consultar el médico hubo mayor percepción de beneficios. Todavía, respectivamente, a esas medidas, identificase en 1 de las 5, 6 de las 9 y 1 de las 5 sentencias sobre barreras mayor percepción de barrera. En las 6 de las 7 sentencias sobre beneficios para usar poco sal, usar poca gordura y tener horas de recreo/diversión hubo mayor percepción de beneficios, pero, respectivamente, a esas medidas hubo mayor percepción de barrera en 3 de las 4, 5 de las 6 y 1 de las 2 sentencias de barreras. Para la mayoría de las medidas estudiadas predominaron creencias sobre beneficios e identificase indicadores para adhesión al tratamiento.

Palabras-clave: hipertensión, educación en salud, enfermería.

\section{Introdução}

A hipertensão arterial é uma doença crônica não transmissível, de múltiplas expressôes, e que se constitui em relevante problema de saúde pública dada as suas implicaçóes econômicas e sociais, cabendo ressaltar que: 1) apresenta um contínuo elevado índice de prevalência e de mortalidade, no contexto nacional e internacional [1];2) é uma doença desencadeada de forma isolada ou está associada ao agravamento de diversas doenças [1] e é multifatorial - associada a fatores de risco modificáveis como tabagismo, uso excessivo de álcool, sedentarismo, obesidade, alimentos calóricos, estresse e, não modificáveis, como sexo, idade e raça; 3) em virtude do seu caráter crônico e incapacitante gera aposentadorias precoces, longo período de internação, alto custo para o tratamento, alteraçóes na auto-estima e autoconceito do indivíduo [2]; 4) aliado ao discurso disciplinador, a pessoa hipertensa apresenta uma condição de vida cerceada, necessitando de monitoramentos constantes, incluindo a "medicalização" da alimentação, da atividade física, além da mudança de hábitos de vida [1]; 5) o patamar de adesão é insatisfatório contribuindo para a morbimortalidade da doença $[2,3]$. Esse panorama revela que é imprescindível a prevençáo e o controle da hipertensão arterial e que a gama de fatores de risco associados à doença implica na mudança de estilo de vida.

Em 2001, o governo federal lançou o Plano de Reorganização da Atenção à Hipertensão Arterial e ao Diabetes Mellitus com o propósito de "vincular as pessoas portadoras desses agravos às unidades de saúde, garantindo-lhes acompanhamento e tratamento sistemático, mediante açóes de capacitaçáo dos profissionais e de reorganização dos serviços" [4]. O grande desafio desse plano é manter a adesão das pessoas hipertensas ao regime terapêutico, fato que náo é observado em virtude da alta prevalência da doença e da baixa taxa de adesão ao tratamento medicamentoso e náo medicamentoso $[2,3]$.

A análise da literatura mostra que vários fatores interferem na adesão ao tratamento da hipertensão arterial e revelam que a adesão é perpassada por dimensôes biológicas, sócio-econômicas, culturais e ambientais. Entre esses fatores destacam-se os relacionados à terapêutica - eficácia em relação aos sinais e sintomas, freqüência de dosagens e horário da tomada de medicamentos, incidência de efeitos colaterais e custo econômico da medicação; ao sistema de saúde - facilidade de acesso, disponibilidade 
de equipe multiprofissional e medicamentos, busca ativa dos casos, sistema de controle da clientela registrada e satisfação do paciente quanto ao atendimento -; e ao indivíduo - sexo, idade, capacidade de adaptação a um novo estilo de vida, experiência e percepção da hipertensão arterial, desejo de aprender sobre a doença e tratamento, motivação para seguir o tratamento, apoio familiar e social $[1,5]$. No entanto, pouco tem sido explorado sobre as crenças de pessoas negras hipertensas relacionadas às medidas de controle da doença - dieta hipossódica e com baixo teor de gordura saturada e colesterol, abandono do tabagismo, redução do consumo de álcool, prática de atividade física, lazer, relaxamento, manutenção do peso corporal ideal, controle da pressão arterial. Entende-se que a condição de estar doente relaciona-se com as crenças e os comportamentos apreendidos e incorporados pelas pessoas por meio da convivência social e cotidiana com a doença. Portanto, é inegável que o controle da pressão arterial não se limita apenas a abordagem do corpo doente. É necessário considerar a experiência de vida e a subjetividade da pessoa como aspectos imprescindíveis no processo de adoecer e de cuidar de si, e é preciso conceber que o controle da hipertensão arterial envolve questôes sociais, culturais, percepçóes e experiências individuais acerca do fenômeno.

Com base no exposto definiu-se como objeto de estudo desta investigação: crenças em saúde de pessoas negras hipertensas sobre barreiras e benefícios relacionados às medidas de controle da doença. Nesse sentido, indagou-se: Quais as crenças em saúde de pessoas negras hipertensas sobre as barreiras e benefícios quanto às medidas de controle da doença?

Assim sendo, constitui-se em objetivo da pesquisa: Identificar as crenças em saúde de pessoas negras hipertensas sobre as barreiras e benefícios relacionados às medidas de controle da doença.

\section{Material e métodos}

Tipo de estudo: trata-se de pesquisa quantitativa, descritiva e exploratória.

Referencial teórico: escolheu-se o Modelo de Crenças em Saúde. Crenças são informações fornecidas pela família e pela sociedade desde a infância, são reforçadas pela cultura e influenciam o comportamento. A premissa básica desse modelo é que o mundo do percebedor e sua motivação de- terminam o seu comportamento e não o ambiente físico [6,7]. O modelo é um instrumento conceitual valioso para compreensão de uma variedade de comportamentos relacionados à saúde: alteraçóes de dieta, obediência a regimes médicos, decisão de parar de fumar, entre outros [7]. Para explicar a ação preventiva, foi publicado por Rosenstock, em 1966 e, posteriormente, aplicado a comportamentos relacionados à manutenção da saúde em geral, incluindo a procura do diagnóstico e o atendimento correto às recomendaçôes médicas [6]. O modelo é demonstrado por quatro variáveis: susceptibilidade percebida - refere-se à percepçáo subjetiva do risco da pessoa em contrair determinada condição ou doença -; severidade percebida - o grau de severidade da doença é avaliado pelo grau de estimulação emocional criado em torno dela e pelas diversas conseqüências biológicas, sociais, emocionais e financeiras que a mesma acarreta -; benefícios percebidos (referem-se à crença na efetividade da ação); e barreiras percebidas - os aspectos negativos da açáo são avaliados em uma análise do tipo custo-benefício, considerando possíveis custos de tempo, dinheiro, esforço e aborrecimento. O potencial para ação é resultado da combinação das variáveis susceptibilidade e severidade percebidas na doença, enquanto que a modalidade de ação é escolhida em função da percepção dos benefícios menos às barreiras percebidas nos comportamentos em saúde. No presente estudo serão investigadas as variáveis benefícios e barreiras percebidas para o controle da hipertensão arterial devido a complexidade do modelo.

A pesquisa foi realizada num centro de saúde do município de Salvador, situado no bairro da Liberdade, que abriga no seu contingente populacional $82,8 \%$ de pessoas da cor preta e parda [8] e que serve de referência para o atendimento de pessoas com hipertensão arterial.

Participaram do estudo 106 pessoas adultas (cor preta e/ou parda), de ambos os gêneros, com diagnóstico médico de hipertensão arterial há no mínimo seis meses, que compareciam ao local de estudo para consulta e/ou verificaçáo da pressão arterial, e que estavam cadastradas no programa de hipertensão do referido centro de saúde. Para o cálculo do tamanho da amostra, assumiu-se a freqüência esperada de benefícios de $50 \%$, com um erro aceitável de 40\%, nível de significância de 5\% e poder da amostra em torno de $60 \%$. A escolha da raça/cor negra deve-se a maior prevalência da hipertensão arterial, quando comparada na branca, 
pelos indivíduos negros e apresentarem a doença mais cedo e níveis tensionais mais elevados. Além disso, como a pesquisa estuda crenças, acredita-se na especificidade delas relacionada à raça/cor negra considerando a história desse povo desde a época da escravidão e a exclusão social [3].

A coleta de dados foi realizada de 17 de julho a 27 de setembro de 2006. Os participantes foram escolhidos de forma aleatória, enquanto aguardavam a verificação da pressão arterial ou a consulta pela equipe multidisciplinar. Após o convite para participar da pesquisa foram explicados os objetivos e, em caso de aquiescência, a pessoa era encaminhada para uma sala privativa, para leitura, esclarecimento e assinatura do termo de Consentimento Livre e Esclarecido. Em seguida a entrevista era iniciada e gravada. Ao término, agradecia-se ao entrevistado a contribuição à pesquisa. Aos participantes foram assegurados o sigilo da identidade pessoal, o direito de abandonar o estudo a qualquer momento e a privacidade. O estudo obteve aprovaçáo do Comitê de Ética e Pesquisa da Secretaria Estadual de Saúde da Bahia.

A parte I do formulário aplicado foi constituída por questóes fechadas sobre dados de caracterização dos participantes. A Parte II foi composta pela "Escala de Crenças", extraída da tese de doutorado de Dela Coleta [7] e obtida sua autorização para uso nesta pesquisa. A Escala apresenta sentenças sobre crenças de barreiras e benefícios relacionados a cada um dos treze comportamentos de saúde referentes às medidas de prevenção e controle da hipertensão arterial, quais sejam: usar pouco sal na comida; comer menos gorduras; comer menos doce, menos açúcar; fazer exercícios várias vezes na semana; evitar preocupaçóes; ter suas horas de lazer e diversão; ter um tempo para descanso, sossego, relaxamento e meditação; procurar medir a pressão arterial; consultar o médico uma vez por ano; não fumar/parar de fumar; evitar bebidas alcoólicas; manter o peso ideal para a idade e a altura; tomar os remédios receitados pelo médico, quando doente. $\mathrm{Na}$ apresentaçáo da escala para cada comportamento de saúde, os itens (sentenças) sobre "benefícios percebidos" foram intercalados aos itens sobre "barreiras percebidas". O levantamento das crenças sobre cada comportamento de saúde era precedido da pergunta: Qual a sua opinião sobre...? Para exemplificar, temos:

\begin{tabular}{|c|c|c|c|c|c|}
\hline $\begin{array}{l}\text { 1. Qual a sua } \\
\text { opinião sobre } \\
\text { usar pouco sal } \\
\text { na comida? }\end{array}$ & $\mathrm{DT}=1$ & $D=2$ & $I=3$ & $\mathrm{C}=4$ & $\mathrm{CT}=5$ \\
\hline $\begin{array}{l}\text { BENSAL - Deve- } \\
\text { se usar pouco } \\
\text { sal na comida } \\
\text { porque ele au- } \\
\text { menta a pressão } \\
\text { arterial. }\end{array}$ & & & & & \\
\hline $\begin{array}{l}\text { BARSAL - A } \\
\text { comida com } \\
\text { pouco sal não } \\
\text { tem gosto. }\end{array}$ & & & & & \\
\hline
\end{tabular}

A escala é apresentada no formato Likert, com cinco níveis de resposta, variando de DT (discordo totalmente $=1), \mathrm{D}($ discordo $=2)$, I (indeciso $=3)$, $\mathrm{C}($ concordo $=4)$ até $\mathrm{CT}$ (concordo totalmente $=$ 5). Para facilitar a resposta, foi entregue ao participante uma figura para que pontuasse a sua resposta à medida que as frases eram lidas, na qual as cores verde, azul, rosa, amarela e vermelha corresponderam a esses níveis.

As entrevistas gravadas foram digitadas nos formulários e os dados foram codificados, digitados e processados no SPSS for Windows. A análise de crenças sobre barreiras e benefícios relacionados às treze medidas de prevenção e controle da hipertensão arterial e dos dados de caracterização foram feitas com base em números absolutos e percentuais.

\section{Resultados}

Dos 106 participantes entrevistados, mais de $2 / 3$ eram mulheres $(73,6 \%)$. A idade mediana foi de 54 anos. Os 50\% dos participantes com idade mais jovem encontravam-se nas faixas etárias $<45$ $(24,5 \%)$ e 45 a 54 (24,5\%). Ainda, que $51 \%$ dos mais velhos, isto é, com idade $\geq 54$ encontravamse na faixa etária de 54 a 63 anos (26,5\%); de 63 a 69 anos $(16 \%)$ e apenas nove pessoas estavam com idade $\geq$ a 70 anos (8,5\%). Apresentaram predominantemente baixa escolaridade (até o $1^{\circ}$ grau $-63,2 \%$ ) e baixa renda familiar, menor que um salário mínimo $(52,8 \%)$. Mais da metade dos participantes exercia atividade profissional, incluindo o trabalho doméstico $(67,0 \%)$ e vivia sem companheiro (61,3\%). Registrou-se predomínio da religião católica (69,8\%). Mais de $2 / 3$ da amostra receberam o diagnóstico médico de hipertensão 
arterial há mais de um ano $(80,2 \%)$; estavam em tratamento medicamentoso e/ou não medicamentoso $(87,7 \%)$.

Os 106 participantes do estudo foram questionados quanto à presença de alguns fatores de risco cardiovascular, doenças associadas e hábitos de vida. Verificou-se que a maioria não fumava $(90,5 \%)$, mas era sedentário $(74,5 \%)$, isto é, não praticava atividade física regular, pelo menos três vezes por semana. Destaca-se ainda que mais da metade da amostra tinha história familiar de doença arterial coronariana. Quase metade informou hipercolesterolemia, mas, surpreendentemente, ainda 43,4\% não sabiam se tinham alteração nos níveis séricos de colesterol. Ainda surpreendente foi a falta de informação dos participantes quanto a doenças associadas à hipertensão arterial, ou seja, 74,5\% e 88,6\% não sabiam, respectivamente, se eram diabéticos ou se haviam sofrido infarto agudo do miocárdio.

A análise das sete sentenças sobre crenças referentes à percepção dos benefícios associados ao uso de pouco sal na comida mostraram que os participantes concordaram em parte ou totalmente quanto aos maléficos do sal para a saúde (BENSAL 2 - 94,3\%); para o aumento da pressão arterial (BENSAL 1 - 98,1\%); e para problemas renais (BENSAL 4 - 69,8\%). Além desses, 97,2\% também concordaram em parte e totalmente que os médicos estão certos ao recomendarem o uso de pouco sal (BENSAL 5) e mais de $2 / 3$ acreditavam que o uso de muito sal leva à perda do paladar e do apetite (BENSAL 3 - 70,8\%). Esses dados mostraram o predomínio da percepção de benefícios referentes a usar pouco sal em 6 sentenças. Entretanto, metade da amostra discordou em parte ou totalmente que a comida com pouco sal é mais gostosa $(50,9 \%)$, apontando essa sentença para a percepção de menos benefícios.

Quanto as 4 sentenças referentes à barreira para usar pouco sal, verificou-se que para três delas a maioria dos participantes concordou em parte ou totalmente que a comida com pouco sal náo tem gosto (BARSAL $1-71,7 \%$ \%); que quem não faz sua própria comida não pode diminuir o sal (BARSAL $3-72,6 \% \%$ ) e que para comer comida com pouco sal a pessoa deve ter força de vontade (BARSAL 4 $92,4 \% \%)$ mostrando maior percepção de barreira. Para a crença "para a maioria das pessoas o sal não faz mal" a maioria dos participantes discordou em parte ou totalmente havendo assim menor percepção de barreira (BARSAL 2- 52,9\%).
Havia 7 sentenças referentes a crenças sobre benefícios e seis sobre barreiras associadas a comer com pouca gordura. A maioria dos participantes concordou em parte e totalmente quanto aos maléficos da comida com gordura por produzir colesterol (BENGORD 1 - 100\%); por fazer mal à saúde (BENGORD 2 -91,5\%); por ser pesada e de difícil digestão (BENGORD 3 - 94,3\%); por causar problemas cardiovasculares (BENGORD $4-99 \%$ ) e (BENGORD 5 - 98,1\%); e por causar obesidade (BENGORD 7 - 99\%). Esses dados demonstraram o predomínio de sentenças sobre a percepção de benefícios referentes a comer comida com menos gordura. Entretanto, quase metade da amostra discordou em parte ou totalmente quanto à sentença "a comida com menos gordura é ruim de gosto” ( BENGORD 6- 49,1\%), apontando a percepção de menos benefícios.

A percepção de menos benefícios quanto à crença de que a comida com menos gordura é ruim de gosto foi reforçada, identificando-se que mais da metade dos participantes percebeu barreiras quanto a essa sentença (BARGORD $3-57,6 \%$ ) e pelo fato de $73,6 \%$ terem considerado que algumas comidas com gordura são deliciosas (BARGORD 1). Se por um lado, como destacado acima, a maioria dos participantes percebeu mais benefícios para comer com menos gordura, também é verdade que houve menor discordância quanto aos prejuízos da comida com gordura (BARGORD 2 - 67,9\%), indicando menor percepção de barreira. A maioria dos participantes concordou em parte e totalmente que é muito difícil fazer regime e não poder comer de tudo (BARGORD 4-88,7\%); que muitas vezes não se tem escolha e a pessoa tem que comer o que está disponível (BARGORD 5 -96,2\%); e que é difícil mudar se uma pessoa está acostumada a comer gorduras (BARGORD 6-88,7\%), indicando maior percepçáo de barreiras para comer comida com menos gordura.

A maioria dos participantes concordou em parte e totalmente quanto aos prejuízos da comida com mais doce, considerando as crenças de que o açúcar engorda, e que causa obesidade (BENDOCE 1 -93,4\%); comer pouco açúcar evita diabetes (BENDOCE 2 - 97,2\%); comer pouco açúcar é bom para a saúde (BENDOCE 3 - 94,3\%); comer doces aumenta o açúcar no sangue (BENDOCE 5 - 95,2\%); o açúcar engrossa o sangue (BENDOCE $6-78,3 \%)$. Esses resultados demonstraram o predomínio da percepção de benefícios referentes a 5 das 
6 sentenças de benéficos associadas a comer comida com menos doce. Todavia, 77,3\% concordaram em parte e totalmente com que se a pessoa gosta muito de doces é impossível não comê-los (BENDOCE 4), apontando a percepção de menor benefício, identificando-se que $71,7 \%$ dos participantes perceberam barreiras quanto a essa sentença (BARDOCE 1). A maioria dos participantes concordou em parte e totalmente que a pessoa que está acostumada a comer doces náo consegue ficar sem comê-los (BARDOCE 2- 81,1\%); doce alimenta (BARDOCE 3 - 81,1\%); uma pessoa tem que comer doce se tiver vontade (BARDOCE $4-81,1 \%$ ), indicando maior percepção de barreiras para 3 das 5 sentenças sobre barreiras para comer comida com menos doce. Mais da metade da amostra discordou em parte e totalmente que seria horrível não poder comer doce (BARDOCE 5-55,7\%), apontando para menor percepçáo de barreira, mas ainda $44,4 \%$ perceberam maior crença sobre barreiras ao concordarem em parte ou totalmente com essa sentença.

Os participantes concordaram em parte e totalmente em todas as 9 sentenças referentes aos benefícios da prática de exercício físico para manter a boa saúde (BENEXERC 1 - 98,9\%); para obter disposição, ânimo (BENEXERC 2 - 97,2\%); para o coração e a circulação (BENEXERC 3 - 98,1\%); para a melhoria da condição física (BENEXERC $4-98,1 \%$ ); para manter a forma e o peso (BENEXERC 5 - 99\%); para evitar o estresse e preservar a saúde mental (BENEXERC 6- 99\%); para as articulaçóes (BENEXERC 7 - 96,2\%); para dormir melhor (BENEXERC 8 -83,9\%); e ter apetite (BENEXERC 9-83,9\%). Embora percebessem benefícios quanto aos resultados proporcionados pelo exercício (BENEXERC 1 a 9), perceberam maior crenças sobre barreiras (em 4 das 5 sentenças) para colocar em prática a atividade física ao concordarem em parte ou totalmente que exercícios são apenas para quem tem tempo (BAREXERC 1- 66,9\%); que fazer exercício exige muitos esforços (BAREXERC 2- 84\%); e que para fazer exercício é preciso ter força de vontade (BAREXERC 3- 96,2\%). Ainda perceberam barreiras para fazer exercício ao considerarem que causa muito cansaço (BAREXERC 4 - 75,5\%). Somente para a sentença "só pratica exercícios quem é desinibido" os participantes discordaram em parte e totalmente (BAREXERC 5-66\%), apontando neste caso a menor percepção de barreiras.

Os participantes concordaram em parte e totalmente quanto aos danos provocados pelas preocupaçóes (BENSTRESS 1 e 2 - 100\% cada); (BENSTRESS 3 - 89,6\%); (BENSTRESS 4 - 99\%); (BENSTRESS 5 - 99,1\%) e (BENSTRESS 6 $95,3 \%$ ), o que denotou maior percepção de benefícios nas 6 sentenças para evitá-las. Os participantes também concordaram em parte e totalmente que "é difícil viver sem preocupaçôes" (BARSTRESS 1 $100 \%$ ); e que "os problemas financeiros não deixam que as pessoas se despreocupem" (BARSTRESS 2 - 100\%). Nas demais sentenças, o predomínio da percepção de barreiras foi de $94,4 \%$ para "o trabalho não permite viver sem preocupaçôes” (BARSTRESS 3); $96,2 \%$ para "quem tem família não consegue se despreocupar" (BARSTRESS 4); e 99\% para "é difícil viver sem preocupaçôes quando se tem muita responsabilidade" (BARSTRESS 5).

Os participantes perceberam crenças em saúde sobre benefícios para ter horas de lazer e diversão, considerando que esta prática serve para descontrair, aliviar as tensóes, esquecer as preocupaçóes e descansar a cabeça (BENLAZER 1 - 99,2\%); o lazer faz bem para a saúde física e mental (BENLAZER $3-100 \%)$; que o homem tem necessidade de lazer, faz parte da vida (BENLAZER $4-100 \%$ ); o lazer ajuda a trabalhar melhor, mais tranqüilo (BENLAZER 5 - 99,1\%); a diversão dá alegria para viver (BENLAZER 6 - 98,1\%); e que o lazer deve ser equilibrado com trabalho (BENLAZER 7 -100\%). Apenas para a sentença "só quem tem tempo pode ter lazer" (BENLAZER 2), a porcentagem para discordo em parte e totalmente foi de 38,7\%, havendo para esses participantes menor percepção de benefício. Quase 2/3 dos participantes concordaram em parte e totalmente que "não dá para ter diversão porque as coisas estão muito caras" (BARLAZER 1- 65,1\%), mostrando maior percepção de barreira para ter horas de lazer e diversão. Metade dos participantes concordou em parte e totalmente e metade discordou em parte e totalmente quanto a "só quem tem saúde pode se divertir ou passear" (BARLAZER 2).

A maioria dos participantes concordou em parte e totalmente quanto aos benefícios do descanso para renovar as energias e restaurar a mente e o corpo (BENRELAX 1 -98,1\%); por oferecer tranqüilidade, ânimo e bem-estar (BENRELAX 2 -100\%); por aliviar as tensôes e evitar o estresse (BENRELAX 3 - 99,1\%); porque descansar ou relaxar faz bem para a saúde (BENRELAX 4 - 99,1\%); porque quem trabalha deve descansar (BENRELAX 5 -100\%); e porque vive mais quem tem tempo para o descanso 
apontando maior percepção de benéficos em todas as 6 sentenças (BENRELAX $6-72,6 \%$ ). A maioria dos participantes concordou em parte e totalmente que só descansa quem tem tempo (BARRELAX $1-53,8 \%)$; que quem não está acostumado, não consegue descansar (BARRELAX $2-83 \%$ ); e que quem trabalha muito não consegue relaxar (BARRELAX 3 - 68\%), indicando maior percepção de barreiras para o comportamento ter um tempo para o descanso, sossego, relaxamento e meditaçáo nas três sentenças sobre barreiras.

A maioria dos participantes percebeu crenças em saúde sobre benefícios para verificação da pressão arterial, considerando que conhecer o valor da pressão arterial informa o estado de saúde e previne problemas de saúde (BENPA 1 e $3 \mathrm{C}$ e CT $=99 \%$ cada), BENPA 2 e 4 C e CT $=100 \%$ cada), BENPA $5 \mathrm{C}$ e $\mathrm{CT}=98,1 \%$ ). A maioria dos participantes discordou em parte e totalmente que quem se sente bem não precisa medir a pressão (BARPA 1 - 83,0\%); que não é importante ou necessário conhecer o valor da pressão (BARPA 2 - 96,2\%); e que náo se deve conhecer o valor da pressão para não se preocupar (BARPA 3 - 93,9\%), indicando menor percepção de barreiras para verificar a pressão arterial. Salienta-se que mais da metade dos participantes concordou ou totalmente que para medir a pressão arterial a pessoa tem que ter tempo (BARPA 4 - 52,8\%); e que ninguém vai pagar consulta só para medir a pressão (BARPA 5 -59,4\%), mostrando maior percepção de barreira.

Chamou a atenção o fato dos participantes concordarem em parte e totalmente em $100 \%$ quanto aos benefícios de consultar o médico uma vez por ano nas três sentenças sobre benéficos (BENMED 1, 2 e 3). A maioria dos participantes concordou em parte e totalmente em 6 das nove sentenças sobre barreiras que: só vai ao médico quem é preocupado com a saúde (BARMED 2 - 89,6\%); deve-se procurar o médico só em caso de necessidade (BARMED 3 - 59,4\%); gasta-se muito tempo com consultas e exames (BARMED $4-89,6 \%$ ); ir ao médico é desagradável (BARMED 7 - 55,7\%); quem vai ao médico acha um monte de doenças (BARMED 8 $80,2 \%$ ); e os exames e tratamentos médicos são muito cansativos (BARMED 9-80,2\%), indicando maior percepção de barreiras. A grande maioria discordou em parte e totalmente que "quem não sente nada não precisa ir ao médico" (BARMED 1 - 82\%); e que "não é importante consultar o médico todo ano" (BARMED 6 - 86,8\%); e 52,9\% (BARMED
5) discordaram em parte e totalmente que "para ir ao médico todo o ano é preciso ter dinheiro". Esses resultados apontaram para menor percepção de barreiras.

Chamou também a atenção o fato dos participantes concordarem em parte e totalmente na sua grande maioria quanto aos benefícios de não fumar ou parar de fumar nas seis sentenças da escala, reconhecendo que: o cigarro prejudica a saúde (BENFUMO 1 - 99\%); o fumo prejudica o pulmão" (BENFUMO 2 - 99,1\%); o fumo incomoda as outras pessoas (BENFUMO $3-99 \%$ ); o fumo tira o apetite (BENFUMO $4-64,2 \%$ ); as pessoas não foram feitas para respirar fumaça (BENFUMO 5 - 100\%); o fumo dá mau hálito (BENFUMO 6 - 91,5\%). Quanto às crenças em saúde sobre as barreiras para não fumar ou parar de fumar, a maioria dos participantes concordou em parte e totalmente em: "é difícil acabar com o vício de fumar" (BARFUMO 1-61,3\%); "o cigarro prejudica a respiração e o fôlego" (BARFUMO 2 - 98,1\%); "fumar faz mal ao coração e à circulação" (BARFUMO 4 - 99,1\%); e "parar de fumar dá angústia" (BARFUMO 6-51,9\%), mostrando maior percepção de barreira. Os participantes discordaram em parte e totalmente em mais de 50\% nas sentenças: "fumar moderadamente não faz mal" (BARFUMO 3 - 84\%); e "fumar acalma e dá prazer" (BARFUMO $5-53,8 \%$ ), apontando menor percepção de barreira quanto a este comportamento.

A maioria dos participantes concordou em parte e totalmente quanto aos prejuízos do consumo do álcool para saúde, considerando as crenças de que "o álcool faz mal à saúde" e "a bebida faz mal ao fígado e ao coração" (BENBEBO 1 e 2 - 98,1\%); " a bebida prejudica o cérebro e os nervos" (BENBEBO 3 - 92,5\%); "o álcool perturba a mente e altera o comportamento" (BENBEBO 4 - 83,1\%); e " beber é um vício, uma fraqueza" (BENBEBO $5-73,6 \%)$. Esses resultados demonstraram o predomínio da percepção de benefícios nas 5 sentenças referentes a evitar bebida alcoólica. Todavia, mais da metade dos participantes discordaram em parte e totalmente que: se tivesse que jamais tomar qualquer bebida alcoólica, sofreria muito (BARBEBO 2 - 67,9\%); uma das melhores coisas da vida é beber numa rodinha de amigos ou de pessoas agradáveis (BARBEBO 3 - 58,5\%); não conseguiria ficar sem beber (BARBEBO 4 - 75,5\%); e é difícil evitar bebidas como a cerveja, o uísque, a pinga ou o vinho, evidenciando menor percepçáo de crenças 
em saúde sobre barreiras quanto a não beber em 3 das cinco sentenças. Ainda 48,1\% (BARBEBO 1) concordaram em parte e totalmente que beber moderadamente náo faz mal; e discordou em parte e totalmente quanto às crenças em relaçáo a mesma sentença $(47,1 \%)$.

Verificou-se o predomínio de crenças em saúde sobre benefícios para manter o peso ideal para a idade e para a altura, em todas as sete sentenças da escala, considerando que os participantes concordaram em parte e totalmente que com o peso adequado a pessoa tem mais disposição e bem estar (BENPESO 1 - 100\%); o excesso de peso faz mal à saúde (BENPESO 2-97,2\%\%); o excesso de peso atrapalha os movimentos e a agilidade da pessoa (BENPESO 3 - 96,2\%); quem está acima do peso pode ter problemas de coração (BENPESO 4 99\%); é bom controlar o peso para manter a forma, ficar elegante (BENPESO 5 - 95,3\%\%); o gordo tem problemas de coluna (BENPESO $6-99,1 \%$ ); a obesidade é uma doença (BENPESO 7 - 95,3\%). Assim, perceberam benefícios para o controle do peso considerando o bem-estar, a preservação da mobilidade, locomoção e estética, e as complicaçóes do excesso de peso. Predominaram crenças em saúde mais relacionadas a barreiras ao concordarem em parte e totalmente que perder peso é um sacrifício (BARPESO 1 78,3\%); que emagrecer é muito difícil (BARPESO 2- 81,1\%); e que a pessoa que não faz sua própria comida não pode escolher o que comer (BARPESO 4- 83,9\%). Por outro lado, predominaram menor crenças sobre barreiras ao discordarem em parte ou totalmente que é melhor comer à vontade do que ficar se preocupando com o peso (BARPESO 3-67,9\%); e que a pessoa que não faz sua própria comida não pode escolher o que comer (BARPESO 5- 86,7\%\%).

Quanto às crenças em saúde, relacionadas a tomar os remédios receitados pelo médico, predominou a percepção de benefícios nas três sentenças (BENREM 1 100\%; BENREM 2 - 98,1\%, BENREM 3 - 96,2\%), ao considerarem que o médico sabe o que faz porque estudou para isso, que os remédios podem curar o problema e que se deve confiar no médico. Assim como os participantes perceberam benefícios para confiar nos médicos (BENREM 3), perceberam menor barreiras (BARREM 2-60,4\%) também para depositar a confiança nesse profissional. Predominaram crenças em saúde mais relacionadas a barreiras, ao concordarem em parte e totalmente que remédios são sempre um veneno, não são naturais (BARREM 1 - 53,7\%); e que os remédios são muito caros (BARREM 3 - 98,1\%). É provável que a baixa condição sócio-econômica tenha influenciado esta crença.

\section{Discussão}

O grupo de pessoas estudado foi caracterizado predominantemente por mulheres $(73,6 \%)$, com idade mediana de 54 anos, pela baixa escolaridade e renda mensal, por náo contar com companheiro (a) e exercer alguma atividade laboral.

De acordo como o Modelo de Crenças em Saúde [6,7], a pessoa, para mudar comportamentos de saúde, necessita primeiramente valorizar os benefícios das mudanças de estilo de vida, ou seja, acreditar que são capazes de reduzir sua suscetibilidade ou severidade da doença. As crenças sobre barreiras podem ser impeditivas para que tome decisóes relacionadas à prevençáo e ao controle de doenças. Como vimos, nos resultados, de modo geral, predominou a percepçáo de crenças sobre benefícios para a maioria das medidas de controle da hipertensão arterial. Embora se acredite que a percepção de benefícios quanto à adoção dessas medidas não implique necessariamente na coerência e efetividade da ação, a crença é, por si só, um forte preditor do comportamento de saúde. Assim, a superação de crenças sobre benefícios em relação às barreiras pode ser um preditor favorável a adesão ao tratamento.

A análise das crenças mostrou, entre as sentenças associadas à percepção de benefícios para usar pouco sal na comida, o predomínio de benefícios, considerando os malefícios que o excesso de sal traz à saúde, o aumento da pressão arterial, e a perda do paladar e do apetite. Embora os participantes pouco tenham discordado dos maléficos do sal perceberam mais crenças sobre barreiras e menos sobre benefícios para a comida pouco palatável quando preparada com pouco sal, confirmando a sensaçáo de prazer vivida ao ingerir comidas com sal. "Assim, optar pela comida preparada com pouco sal implica em fazer esforço, ter menos prazer, e ter que estar envolvido no preparo do alimento. Nesse sentido, as pessoas precisam ser ajudadas a utilizar outros elementos culinários no preparo dos alimentos, como, por exemplo, uso de mais limáo ao invés do sal, vinagre, azeite doce, entre outros, a fim de melhorar o sabor da comida. Vale ressaltar que a culinária nordestina, 
mais especificamente a baiana, é rica em pratos tradicionais preparados com muito sal, muita gordura e muitos condimentos. Assim, as pessoas que têm hipertensão arterial, como o grupo entrevistado neste estudo, necessitam também da ajuda de amigos e familiares para manter a prática saudável de usar pouco sal na comida [9].

Se por um lado, a maioria dos participantes viu mais benefícios e menos barreiras para comer com menos gordura devido aos danos que acarreta, indicando menos percepçáo de barreira, a maioria dos participantes, nas sentenças sobre barreira, concordou em parte e totalmente que é muito difícil fazer regime e não poder comer de tudo $(88,7 \%)$, que muitas vezes, por não dispor de escolhas, a pessoa tem que comer o que se encontra disponível $(96,2 \%)$ e que é difícil mudar se uma pessoa está acostumada a comer gorduras $(88,7 \%)$, indicando maior percepção de barreiras para comer comida menos gordurosa. O predomínio da percepçáo de crenças de menor benefício ou maior barreira para comer comida com menos gordura foi predominantemente atrelado à diminuição do seu paladar, à restrição na escolha do que comer e a dificuldade de mudança desse hábito de vida. Vale ressaltar que a baixa renda pode influenciar na crença de que muitas vezes, porque não há o que escolher, a pessoa come o que existe e, desse modo, estes fatos se constituem em barreira para evitar comida com menos gorduras. Para a pessoa hipertensa, é importante uma dieta equilibrada, com reduzido teor de sódio, baixos níveis de gordura saturada e restrição ao açúcar refinado. Contudo, ao enfocar sobre a reeducação alimentar, é preciso levar em conta que, o comer, entre as providências voltadas à manutenção da saúde, é das mais importantes da vida, podendo ser sentido como um prazer, uma grande compensaçáo ou até mesmo como uma forma de sublimação de seus problemas [10].

A predominância dos benefícios quanto a fazer exercícios foi associada as suas vantagens para melhorar a condição de saúde, e a percepção de barreiras ao fato de que fazer exercício implica em sacrifício pessoal, cansaço, tempo disponível, não sendo tão fácil aderir à prática da atividade física apesar de seus benefícios. Essas barreiras indicam as possíveis dificuldades encontradas pela maioria dos sedentários deste estudo para mudança desse comportamento.

Estudos recentes evidenciaram o efeito do estresse psicoemocional na reatividade cardiovas- cular e da pressão arterial [11]. Quanto ao estresse, nossos resultados mostraram que, a despeito dos benefícios desfrutados por um indivíduo capaz de evitar preocupaçôes, as barreiras estão estreitamente ligadas à crença de que a preocupação é fator inerente à própria condição do ser humano e da vida, ou seja, enquanto ser humano ativo, que trabalha e se relaciona, inserido em um contexto social muitas vezes adverso a uma vida digna. Nesse sentido, evitar preocupaçóes é um desafio para o controle da saúde e prevenção de doenças, pois sofre influência do meio ambiente, dos comportamentos das pessoas e das condiçóes de vida. Há que se destacar que parece difícil a pessoa querer se afastar, evitar, ou ocultar o que talvez considere como intrínseco à vida, uma preocupação vital.

Quanto a crenças sobre ter horas de lazer e diversão vimos que os participantes valorizaram a importância dessa prática para esquecer os problemas e melhorar a qualidade de vida, salvo que a baixa condição sócio-econômica se constitui como uma barreira para a ação e a percepção do encarecimento dos meios de lazer, selecionando e excluindo uma grande parte da sociedade. Aí está também um desafio para as autoridades públicas, no sentido de investirem em práticas públicas de lazer e diversão.

A maioria dos participantes concordou em parte e totalmente quanto aos benefícios associados a ter um tempo para descanso, relaxamento, meditação em todas as sentenças, mas também perceberam predominantemente barreiras nas sentenças sobre barreiras para esse comportamento, mostrando que o descanso implica em tempo, em saber descansar e não trabalhar tanto. Essas crenças sobre barreiras somadas as condiçóes sócio-econômicas dos participantes do estudo podem ser restritivas a mudança desse comportamento.

Grande parte dos participantes percebeu mais benefícios e menos barreiras para verificação da pressão arterial, considerando que conhecer o seu valor informa o estado de saúde e previne problemas de saúde, revelando que esse é um parâmetro valorizado por eles como forma de indicar o seu controle. Contrapondo-se a isto, o fato de mais da metade concordar, nas sentenças sobre barreiras, que para medir a pressão arterial a pessoa tem que ter tempo $(52,8 \%)$; e que ninguém vai pagar consulta só para medir a pressão $(59,4 \%)$, mostrou maior percepçáo de barreira e evidenciou a não valorização da importância do rigor na verificaçáo da pressáo 
arterial. Alavarce et al. [12] sugerem que essa medida seja realizada em todas as consultas médicas, independente da especialidade, pois se trata de um procedimento fácil de ser executado e, se realizado corretamente, é uma das maneiras mais rápidas, seguras e eficazes de se detectar a doença.

Chamou atenção o fato de os participantes concordarem em parte e totalmente em 100\% quanto aos benefícios de consultar o médico uma vez por ano. Se por um lado, evidenciou-se maior percepção de barreiras para a consulta médica, por outro, para a grande maioria dos participantes, identificou-se menor percepção de barreiras para as crenças: "quem não sente nada náo precisa ir ao médico", "não é importante consultar o médico todo ano" e "para ir ao médico todo o ano é preciso ter dinheiro". A percepção de barreiras para consultar o médico uma vez por ano foi associada ao custo do atendimento médico, ao dispêndio de tempo para exames e consultas, a possibilidade de defrontar-se com doenças e a natureza exaustiva dos exames e tratamentos. Um estudo desenvolvido com pessoas hipertensas em Minas Gerais apontou que as principais dificuldades de acesso à consulta médica foram à situação financeira, o deslocamento e à disponibilidade de tempo para marcar a consulta. Os entrevistados que relataram não ter dificuldades para se consultar explicaram que é fácil porque podem pagar a consulta. É interessante salientar que alguns dos entrevistados preferiram pagar a consulta, quando podiam, porque achavam que $\mathrm{o}$ atendimento era melhor e a consulta mais prolongada [13].

Para as crenças em saúde quanto a não fumar ou parar de fumar observou-se também o predomínio de benefícios para todas as sentenças devido à percepção dos danos gerados pelo cigarro. Corroborou com a percepção de benefícios a identificação de menor percentual de barreira para a crença "fumar moderadamente não faz mal" e "fumar acalma e dá prazer". O predomínio da percepção de barreira foi associado a crenças relacionadas à dificuldade de parar de fumar. Estes resultados mostram que os participantes reconhecem os malefícios provocados pelo fumo o que pode ter influenciado na opção de não fumar feita por $90,5 \%$ deles. Além disso, retratou a percepçáo do desafio a ser encarado pela equipe de saúde e pelo indivíduo quando opta pela interrupção do vício.

Para as crenças em saúde associadas a evitar bebidas alcoólicas observou-se também o predomínio de benefícios para a maioria das sentenças devido a percepção dos danos gerados pela bebida alcoólica ingerida em excesso, mostrando que os participantes estáo conscientes do controle dessa medida para evitar problemas de saúde. Todavia, para mais da metade dos participantes identificouse crenças associadas a barreiras para evitar bebidas alcoólicas nas seguintes sentenças: se tivesse que jamais tomar qualquer bebida alcoólica, sofreria muito, uma das melhores coisas da vida é beber numa rodinha de amigos ou de pessoas agradáveis, não conseguiria ficar sem beber, e é difícil evitar bebidas como a cerveja, o uísque, a pinga ou o vinho. Esses dados mostram a dificuldade para abandonar um hábito considerado prazeroso ou um vício. É importante alertar as pessoas hipertensas que apreciam a bebida alcoólica que não é necessário abandoná-las para controlar a pressão arterial, mas limitar o consumo (máximo 30g/dia de etanol para homens e $15 \mathrm{~g} /$ dia para mulheres ou pessoas de baixo peso). Todavia, aos que náo se enquadrarem nesses limites de consumo é recomendado o abandono e para tal intervençóes individualizadas podem ser implementadas, pois estudos demonstraram que a redução da ingestão de bebida alcoólica pode reduzir a pressão arterial naqueles que consomem grandes quantidades [11].

Verificou-se também o predomínio de crenças em saúde sobre benéficos para manter o peso ideal para a idade e para a altura em todas as sentenças considerando o bem-estar, a preservação da mobilidade, locomoçáo e estética, e as complicaçôes do excesso de peso, assim como, o predomínio da percepção de menos barreiras para as crenças "é melhor comer à vontade do que ficar se preocupando com o peso" e "a pessoa que náo faz sua própria comida não pode escolher o que comer”. Chamou a atenção que a maior percepção de barreiras para manter o peso ideal foi mais associada a esforços pessoais para adesão ao regime alimentar ou a prática de atividade física.

Quanto às crenças em saúde relacionadas a tomar os remédios receitados pelo médico predominou a percepçáo de benefícios e menos barreiras para depositar a confiança nesse profissional. $\mathrm{O}$ predomínio de barreiras para as crenças em saúde relacionadas ao alto custo dos remédios pode ter relação com a baixa condição sócio-econômica dos participantes. Estudo realizado com pessoas hipertensas para identificar os fatores que contribuíam para que não tomassem os medicamentos mostrou que, $89 \%$ referiram baixa adesáo devido ao alto 
custo, $67 \%$ por ter de tomar várias vezes ao dia e 54\% devido aos efeitos indesejáveis [14].

Embora os participantes do estudo tenham percebido mais crenças em saúde, referentes aos benefícios quanto às medidas de prevenção e controle da hipertensão arterial, e que as mudanças comportamentais representam o abandono de alguns prazeres para pessoas que lutam para sobreviver em condiçóes de vida de pobreza, é sempre necessário que a educação em saúde se faça de modo a contemplar a individualidade e o contexto social da pessoa. Os educadores em saúde, incluindo a enfermeira, devem exercer a função de encorajar as pessoas hipertensas a assumirem a responsabilidade de proteger a própria saúde, de ajudá-las a encontrar, no âmbito de suas possibilidades, a adoção de hábitos e estilos de vida saudáveis, no intuito de promover o controle e a prevenção de agravos decorrentes da doença.

Sem dúvida, a aderência ao tratamento medicamentoso e não medicamentoso implica em mudanças de comportamento significativas para determinados indivíduos. A sociedade atual propicia a adoção de estilos de vida não saudáveis incluindo hábitos alimentares incorretos, com predomínio de alimentos gordurosos, hipercalóricos, contribuindo para o sobrepeso, dislipidemias, consumo excessivo de álcool, além da elevada prevalência de indivíduos sedentários e tabagistas. Vale lembrar ainda que o consumo de tabaco no país ainda é estimulado pelos meios de comunicação em função da dificuldade em instituir-se uma política de saúde mais rígida para coibir essa indústria.

Náo podemos perder de vista que o controle da hipertensão arterial implica em mudanças comportamentais importantes, o que requer que a equipe de saúde empreenda esforços na abordagem psicossocial na atenção à pessoa hipertensa. Portanto, a superação do modelo de atenção à saúde vigente demanda diferentes investimentos na formaçáo e intervenção profissional, visando a atençáo da pessoa ao invés do corpo doente. Pressupóe compreender diferentes modos de ser e de viver e qual a experiência e expectativa de uma pessoa diante do convívio com a doença crônica, optando por tratar-se ou não [15]. Como a pessoa pensa, sente, o que conhece, suas crenças, valores e atitudes e o contexto social em que o comportamento se processa sáo fatores essenciais a serem considerados no processo terapêutico e, para propor-se uma estratégia pedagógica efetiva [15].

A modificação do hábito alimentar, o abando- no do álcool e do fumo, bem como, a adoção de um estilo de vida mais saudável podem constituir para alguns indivíduos um desafio quase que insuperável. Porém, se considerarmos a importância do controle desses fatores não só para o controle da hipertensão arterial, mas, para a melhor qualidade de vida do indivíduo, fica clara a necessidade do compromisso da equipe de saúde no auxílio à pessoa hipertensa para a valorização e prática de um estilo de vida saudável.

O enfermeiro pode ser identificado como um elemento de confiança no compartilhamento, na escuta sensível e intervenção sobre os problemas de saúde do indivíduo hipertenso. $\mathrm{Na}$ maioria das vezes, as pessoas hipertensas desejam não só esclarecimentos para suas dúvidas, mas, também, alguém que se solidarize com o sofrimento psicossocial e considere no cuidado a saúde a relação entre sua história de vida, comportamentos e o processo de adoecer, suas crenças em saúde e o contexto social [15]. Além disso, a despeito de qualquer ação eficaz para a mudança de atitude de uma pessoa, esta somente poderá ocorrer se ele estiver motivado e contar com suportes imprescindíveis da estrutura econômica e social [15].

\section{Conclusão}

A análise das crenças em saúde sobre as medidas de controle da hipertensão arterial evidenciou que para comer menos doce, verificar a pressáo arterial, manter peso ideal e parar de fumar predominaram benefícios em todas as sentenças e barreiras em 3 das 5 referentes a cada medida. Em todas as sentenças relativas a evitar preocupação e ter tempo para relaxamento predominaram benefícios e barreiras. Nas sentenças sobre benefícios para evitar bebidas alcoólicas, praticar exercício e consultar o médico houve maior percepção de benefícios. Todavia, respectivamente, a essas medidas, identificou-se em 1 das 5, 6 das 9 e 1 das 5 sentenças sobre barreiras maior percepçáo de barreira. Nas 6 das 7 sentenças sobre benefícios para usar pouco sal, usar pouca gordura e ter horas de lazer/diversão houve maior percepção de benefícios porém, respectivamente, a essas medidas houve maior percepção de barreira em 3 das 4, 5 das 6 e 1 das 2 sentenças sobre barreiras. Para a maioria das medidas estudadas predominou crenças sobre benefícios e o estudo contribuiu para identificação de indicadores que interferem na adesáo ao tratamento da hipertensáo arterial e 
para a reflexão e implementação de novas formas de atenção a pessoas hipertensas, a fim de retardar as complicaçôes provocadas pela doença por meio de seu controle efetivo.

\section{Referências}

1. Ide CAC. Atenção ao doente crônico: um sistema teórico-instrumental em ressignificação. In: Pierin AMG, ed. Hipertensão arterial: uma proposta para o cuidar. Barueri: Manole; 2004. p. 1-9.

2. Pierin AMG. O desafio do controle da hipertensão arterial e a adesão ao tratamento. In: Pierin, AMG. Hipertensão arterial: uma proposta para o cuidar. 1a ed. Barueri: São Paulo; 2004. p. 275-89.

3. The seventh report of The Joint National Committee on detection, evaluation and treatment of high blood pressure. JAMA 2003; 289(19):2560-71.

4. Brasil. Ministério da Saúde. Secretaria de políticas de saúde. Cadernos de atenção básica. Hipertensão arterial sistêmica e diabetes mellitus, Protocolo. Brasília: MS; 2001.

5. Araújo GBS. Adesão ao tratamento anti- hipertensivo: análise conceitual [dissertação]. João Pessoa: Centro de Ciências da Saúde, Universidade Federal da Paraíba; 2002. 119p.

6. Dela Coleta MF. O modelo de crenças em saúde: uma aplicação a comportamentos de prevenção e controle da doença [Tese]. Brasília: Instituto de Psicologia, Universidade de Brasília; 1995. 334p.

7. Stuchi RAG. A persuasão como estratégia de deslocamento de crenças: de comportamentos de risco para comportamentos preventivos em doença coronariana [tese]. Ribeirão Preto: Escola de Enfermagem de Ribeirão Preto; 2004.

8. Instituto Brasileiro de Geografia e Estatística. Resultados da amostra do censo demográfico 2000. Área de ponderação Liberdade, Sieiro e Japão [online]; 2000;. Salvador. [citado 2006 Nov 1]. Disponível em URL: http://www.ibge.gov.br/home/estatistica/populacao/ censo2000.

9. Pires CGS. Crenças de pessoas negras hipertensas: barreiras e benefícios relacionados às medidas de prevenção e controle da doença. [dissertação]. Salvador: Programa de Pós Graduação da Escola de Enfermagem, Universidade Federal da Bahia; 2007.

10. Bastos DS, Borenstein MS. Identificando os déficits de autocuidado de clientes hipertensos de um Centro Municipal de saúde. Texto Contexto Enfermagem 2004;13(1):92-9.

11. Silva GV, Ortega KC, Colombo FC, Rosa EC, Toscano PRP, Jardim PCV, et al. V Diretrizes Brasileiras de Hipertensão Arterial. Rev Soc Bras Hipertens 2006;6(5):1-47.

12. Alavarce DC, Pierin AMG, Mion Jr, D. A pressão arterial está sendo medida? Rev Esc Enfermagem USP 2000;34(1):84-90.

13. Eirmo JOA, Costa MFL, Uchóa E. Projeto Bambuí: maneiras de pensar e agir de idosos hipertensos. Cad Saúde Pública 2004;20(4):1029-40.

14. Gusmão JL, Mion JR, D. Adesão ao tratamento: conceito. Rev Bras Hipertens 2006; 13(1):23-25.

15. Mussi FC. Desconforto, modelo biomédico e enfermagem: reflexôes com base na experiência de homens infartados. Acta Paul Enferm 2003;16(3):77-97. 